\title{
O cooperativismo e o desenvolvimento local: um estudo da cooperativa de crédito Sicredi União MS/TO - Comitê Ação Social
}

\author{
Cooperativism and local development: a study of credit cooperative Sicredi \\ União MS/TO - Social Action Committee
Cooperativismo y desarrollo local: un estudio de crédito cooperativo Sicredi União MS/TO - Comité de Acción Social

\author{
Heitor Romero Marques ${ }^{1}$ \\ Jéssica Ojeda da Costa ${ }^{1}$
}

Recebido em 10/03/2020; revisado e aprovado em 17/07/2020; aceito em 30/07/2020 DOI: http://dx.doi.org/10.20435/inter.v22i2.2961

\begin{abstract}
Resumo: Esta pesquisa tem como enfoque temático abordar um estudo de caso sobre o cooperativismo e o desenvolvimento local, com foco no Comitê Ação Social da Cooperativa de Crédito Sicredi União MS/TO e no impacto de suas ações no desenvolvimento local da cidade de Campo Grande, MS. A metodologia utilizada foi a revisão bibliográfica, análise documental e entrevista com os representantes do comitê. A relevância desta temática está voltada aos resultados da influência do comitê social no desenvolvimento dos cooperados e da comunidade local. De modo geral, o presente objeto consiste em compreender a atuação do comitê da Cooperativa e sua importância na geração de benefícios econômicos, culturais, sociais e ambientais.
\end{abstract}

Palavras-chave: desenvolvimento local; cooperativa; Sicredi; Comitê Ação Social.

Abstract: This research has as a thematic focus to address a case study on Cooperativism and Local Development with a focus on the Social Action Committee of the Credit Cooperative Sicredi União MS/TO and the impact of its actions on the local development of the city of Campo Grande, MS. The methodology used was the bibliographic review, document analysis and interview with the representatives of the committee. The relevance of this theme is focused on the results of the influence of the social committee on the development of cooperative members and the local community. In general, the present object is to understand the performance of the cooperative committee and its importance in generating economic, cultural, social and environmental benefits.

Keywords: local development; cooperative; Sicredi; Social Action Committee.

Resumen: Esta investigación tiene como enfoque temático abordar un estudio de caso sobre Cooperativismo y Desarrollo Local con un enfoque en el Comité de Acción Social de la Cooperativa de Crédito Sicredi União MS/TO y el impacto de sus acciones en el desarrollo local de la ciudad de Campo Grande, MS. La metodología utilizada fue la revisión bibliográfica, el análisis de documentos y la entrevista con los representantes del comité. La relevancia de este tema se centra en los resultados de la influencia del comité social en el desarrollo de los miembros de la cooperativa y la comunidad local. En general, el objetivo actual es comprender el desempeño del comité cooperativo y su importancia en la generación de beneficios económicos, culturales, sociales y ambientales.

Palabras clave: desarrollo local; cooperativa; Sicredi; Comité Acción Social.

\section{INTRODUÇÃO}

Esta pesquisa busca apresentar um estudo de caso do Comitê Ação Social da Cooperativa de Crédito Sicredi União MS/TO e seus impactos no desenvolvimento local da cidade de Campo Grande, Mato Grosso do Sul (MS), capital de atuação do comitê.

A importância deste estudo se justifica na tentativa de evidenciar como as ações das cooperativas têm cumprido o seu papel, atingindo o desenvolvimento da comunidade local de modo a melhorar a sociedade na qual estão inseridas. Ademais, é relevante debater também

\footnotetext{
${ }^{1}$ Universidade Católico Dom Bosco (UCDB), Campo Grande, Mato Grosso do Sul, Brasil.
} 
sobre a atuação da cooperativa no 70 Princípio do Cooperativismo, bem como demonstrar sua responsabilidade e seu comprometimento por meio de normativos, informativos e estatuto desenvolvidos pela Cooperativa Sicredi União MS/TO.

O objetivo geral da pesquisa que deu origem a este trabalho consistiu em compreender a atuação do Comitê Ação Social e seus impactos no desenvolvimento local e, por fim, discorrer sobre o histórico do cooperativismo, sua evolução ao longo do tempo, conceituações, princípios do Cooperativismo, desenvolvimento local e seus conceitos e a realização do estudo de caso sobre o comitê em questão.

A metodologia de pesquisa utilizada foi a revisão bibliográfica, por meio de revisão de literaturas que abordam o tema tratado neste estudo. A revisão bibliográfica é desenvolvida na utilização de materiais já elaborados como artigos, livros, teses e abrange um caráter exploratório, aprofundando em um maior conhecimento sobre o problema, aperfeiçoando ideias ou descobertas.

Utilizou-se também a metodologia de análise documental, examinando normativos e o estatuto da Cooperativa de Crédito Sicredi União MS/TO. A análise documental vale-se de documentos como material primordial, dos quais seja possível extrair informações e, organizálas, concluindo na interpretação voltada para o auxílio da pesquisa.

A metodologia da entrevista realizada com os representantes atuais do Comitê Ação Social, é no sentido de colher dados primários, notadamente aqueles voltados para a fundação e organização da instituição em foco.

A relevância deste desse estudo direciona-se à contribuição no cunho social e científico. Está propício socialmente na compreensão de melhoria e bem-estar socioeconômico da sociedade, por meio de ações elaboradas pelas cooperativas que beneficiam a comunidade local, enquanto a relevância cientifica inclina-se teoricamente ao desbravamento do assunto em questão para pesquisadores e simpatizantes do tema abordado.

\section{ASPECTOS HISTÓRICOS DO COOPERATIVISMO - CONCEITUAÇÕES E EVOLUÇÃO}

Ainda que não seja possível o esgotamento do assunto em tela, apresentam-se aqui alguns dados históricos do cooperativismo, na medida em que são apresentados alguns de seus conceitos.

O marco inicial do cooperativismo mundial surgiu em Rochdale, na Inglaterra, no ano de 1892, com 28 operários fundamentados na cooperação e mutualidade, mostrando oposição ao capitalismo por meio do cooperativismo como um movimento alternativo (SALES, 2010).

O movimento cooperativista perdura até os dias de hoje, por meio das cooperativas. As cooperativas são exemplos de iniciativas locais de desenvolvimento econômico e social, visto que visam a ações coletivas para um bem em comum, de maneira solidária e participativa, possibilitando a criação de formas justas, solidárias e de agregação de renda (OLIVEIRA, 2004).

De modo geral, entidades visam a interesses altruístas ou generalizantes, enquanto as cooperativas estão focadas no bem-estar e no desenvolvimento de cada indivíduo desenvolvendo um modelo solidário (RIBEIRO; ALVES, 2010).

O cooperativismo é considerado um sistema que surge como solução dos problemas sociais, com o enfoque na cooperação. Enquanto isso, uma cooperativa, de acordo com o Dicionário Aurélio (1997), é uma sociedade ou empresa formada por indivíduos de um certo grupo econômico ou social que tem por finalidade o bem em comum de uma determinada atividade econômica.

No Brasil (1971), as cooperativas são amparadas pela Lei n. 5764/71, de dezembro de 1971, que estabelece em seu Art. 4 ㅇ o que são as cooperativas: 
Art. 4을 As cooperativas são sociedades de pessoas, com forma e natureza jurídica próprias, de natureza civil, não sujeitas a falência, constituídas para prestar serviços aos associados, distinguindo-se das demais sociedades.

Convém ressaltar que o cooperativismo no Brasil surgiu a partir de 1932, devido à reestruturação das atividades agrícolas estimuladas pelo poder público, bem como pela promulgação da lei do cooperativismo brasileiro (PINHO, 1996).

A primeira cooperativa de crédito brasileira foi fundada em 28 de dezembro de 1902, no município de Nova Petrópolis, Rio Grande do Sul (RS), e constitui a atual Sicredi Pioneira RS (SICREDI, 2020). Já a cooperativa em estudo foi fundada em 26 de agosto de 1988, pela vontade de 45 servidores da Universidade Federal de Mato Grosso do Sul (UFMS), nascendo, assim, a CRED-UFMS, atualmente denominada Sicredi União MS/TO (SICREDI, 2020).

\section{PRINCÍPIOS DO COOPERATIVISMO}

Para que a atuação de uma cooperativa seja efetiva, ela orienta-se pelos sete princípios do cooperativismo, os quais foram anunciados em 1995, no Congresso da Aliança Cooperativa Internacional (ACI) (SEBRAE, 2019). Esses princípios são a base, a essência e o diferencial de uma cooperativa. Seguem abaixo os 7 princípios do cooperativismo segundo o SEBRAE (2019):

10 Adesão livre e aberta de sócios: As cooperativas são organizações abertas à participação de todos, independentemente de sexo, raça, classe social, opção política ou religiosa. Para participar, a pessoa deve conhecer e decidir se tem condições de cumprir os acordos estabelecidos pela maioria.

2o Administração e controle democrático dos sócios: As cooperativas são organizações democráticas controladas por seus associados, que participam ativamente na fixação de suas políticas e nas tomadas de decisões. Homens e mulheres, reunidos em assembleia, discutem e votam os objetivos e as metas do trabalho conjunto e elegem os representantes que administrarão a sociedade. Cada associado representa um voto, não importando se alguns detêm mais cotas do que outros.

3o Participação econômica dos sócios: Todos contribuem igualmente para a formação do capital da cooperativa, e ele é controlado democraticamente. Ao menos parte desse capital é, geralmente, de propriedade comum da cooperativa.

40 Autonomia e independência: $O$ funcionamento da empresa é controlado pelos sócios. Nas relações com outras organizações, inclusive governos, ou quando obtêm capital de fontes externas, fazem-no de modo que garantam o controle democrático pelos seus associados e mantenham essa autonomia intacta.

5o Educação, treinamento e educação: As cooperativas fornecem educação e treinamento aos seus sócios, aos representantes eleitos, administradores e empregados, para que possam contribuir efetivamente ao desenvolvimento de sua cooperativa. Elas informam ao público em geral, particularmente aos jovens e líderes de opinião, a natureza e os benefícios da cooperação. A cooperativa de crédito destina pelo menos $5 \%$ das sobras brutas para a formação de um fundo com essa finalidade - Fundo de Assistência Técnica, Educacional e Social (FATES).

60 Parcerias entre cooperativas: Para o fortalecimento do cooperativismo, é importante que haja intercâmbio de informações, produtos e serviços, viabilizando o setor como atividade socioeconômica. Com isso, as cooperativas servem seus associados mais efetivamente e consolidam o movimento, trabalhando juntas por meio de estruturas locais, regionais, nacionais e internacionais.

70 Interesse pela comunidade: As cooperativas trabalham para o bem-estar de suas comunidades, por meio da execução de políticas aprovadas por seus associados, as quais englobam programas socioculturais, realizados em parceria com o governo e outras entidades civis. 
Esses princípios são bases para que as cooperativas possam atuar com um norte, ou seja, direcionem suas performances para seu melhor desenvolvimento.

\section{DESENVOLVIMENTO REGIONAL/LOCAL}

Partindo dos diferenciais Sicredi (2020) encontrados no site da Cooperativa Sicredi União $\mathrm{MS} / \mathrm{TO}$, nota-se, entre os tópicos, o desenvolvimento regional. De acordo com a cooperativa, o desenvolvimento regional segue a linhagem abaixo, de forma macro:

Na cooperativa de crédito, você participa dos resultados. E os recursos são sempre reinvestidos na comunidade. As cooperativas, trabalham captando e emprestando recursos de associados para associados. Isso faz com que os recursos aplicados por um associado sejam emprestados, no máximo em algum município vizinho, evitando que a movimentação financeira saia da região. Esse fluxo gera novos empregos, investimentos e, acima de tudo, melhoria na qualidade de vida da comunidade. (SICREDI, 2020).

Outros dois tópicos importantes dos diferenciais elencados pela cooperativa em seu site são: Modelo Agregador de Renda e Relacionamento. O Modelo Agregador de Renda visa agregar renda aos seus associados e, de maneira indireta, à comunidade local, devido a sua natureza ser cooperativista. Pelo requisito Relacionamento, as cooperativas procuram maior envolvimento dos associados (donos) e buscam ativamente a participação na comunidade em que estão inseridas.

Nota-se que a cooperativa preza pelo desenvolvimento e envolvimento com a comunidade em que está alocada. Investigando nos documentos oficiais da cooperativa, evidenciou-se no Estatuto Social (2017), no Capítulo II, Art. 3o, parágrafo 1o, esse comprometimento da cooperativa com o desenvolvimento regional:

A Cooperativa terá o propósito, também, da educação, formação e informação para seu quadro social, visando fomentar a expansão do cooperativismo de crédito, atendendo, entre outros, aos princípios da mutualidade e do desenvolvimento regional sustentável.

Em um âmbito geral, a Cooperativa de Crédito Sicredi União MS/TO possui agências de atendimento localizadas nos estados de Mato Grosso do Sul, Tocantins e Bahia, pelas quais se compromete a gerar um desenvolvimento regional, resultando, assim, em um desenvolvimento local nas comunidades onde há atuação.

No entendimento de Rodrigues e Castilho (2016), não existe um conceito pronto e acabado de desenvolvimento local, uma vez que se trata de um processo ainda em construção. Ele possui vários vetores que podem ser importantes para ajudar a entender melhor os processos dos quais faz parte e que, no fundo, ajuda a construir.

Particularmente importante é que, na teoria do desenvolvimento local, valorizam-se as relações interpessoais na construção das sinergias, visando à resolução dos problemas comuns que dizem respeito a toda a comunidade.

Sobre o entendimento de comunidade, Bartler (2015) afirma que uma comunidade não se resume às pessoas que a constituem. De um modo geral, ela já existia antes dos seus atuais membros terem sequer nascido e, provavelmente, continuará a existir mesmo depois dos seus atuais membros terem desaparecido. É algo que transcende cada um dos seus componentes, os residentes atuais ou os próprios membros da comunidade. Uma comunidade pode incluir membros que se mudaram temporariamente para outros locais. Eles podem planear um eventual regresso, mas nem todos o fazem. 
Outra particularidade que caracteriza a comunidade, segundo o pensamento de Bauman (2012), é que nela podemos contar com a boa vontade dos outros. Caso tropeçarmos e cairmos, os outros nos ajudarão a ficar de pé outra vez. Ninguém vai rir de nós, nem ridicularizar nossa falta de jeito e alegrar-se com nossa desgraça. Se dermos um mau passo, ainda podemos nos confessar, dar explicações e pedir desculpas, arrepender-nos, se necessário; as pessoas ouvirão com simpatia e nos perdoarão, de modo que ninguém fique ressentido para sempre. $\mathrm{E}$ sempre haverá alguém para nos dar a mão em momentos de tristeza. Quando passarmos por momentos difíceis e por necessidades sérias, as pessoas não pedirão fiança antes de decidirem se nos ajudarão; não perguntarão como e quando retribuiremos, mas sim do que precisamos. E raramente dirão que não é seu dever ajudarmos nem recusarão seu apoio só porque não há um contrato entre nós que as obrigue a fazê-lo, ou porque tenhamos deixado de ler as entrelinhas. Nosso dever, pura e simplesmente, é ajudar uns aos outros e, assim, temos pura e simplesmente o direito de esperar obter a ajuda de que precisamos.

Como se pode inferir do acima dito, nas pequenas comunidades, imperam as relações primárias e, nas comunidades mais extensas, as relações secundárias. Em assim sendo, nas pequenas comunidades as pessoas têm mais possibilidades de partilharem suas dificuldades e encontrarem juntas as soluções para seus problemas. Isso equivale à sinergia das forças endógenas, ou seja, as pessoas se unem para resolver seus problemas a partir de suas potencialidades.

Segundo Buarque (2002), desenvolvimento local é processo interno que ocorre em pequenos espaços territoriais e com um conjunto de indivíduos dispostos ao desenvolvimento socioeconômico da população, com o intuito de melhorar o bem-estar e a economia do local.

Ainda que o desenvolvimento local seja um processo sinérgico das forças endógenas, a comunidade correspondente não deve se enclausurar em suas fronteiras, pois isso causaria localismo e isolacionismo, com riscos altamente prejudiciais. Isso equivale à busca de autonomia com grau de competitividade, mediante manutenção das redes de relações sociais, comerciais, culturais etc. Do ponto de vista de Bauman (2012, p. 12):

Há um preço a pagar pelo privilégio de 'viver em comunidade' - e ele é pequeno e até invisível só enquanto a comunidade for um sonho. O preço é pago em forma de liberdade, também chamada 'autonomia', 'direito à autoafirmação' e 'à identidade'. Qualquer que seja a escolha, ganha-se alguma coisa e perde-se outra. Não ter comunidade significa não ter proteção; alcançar a comunidade, se isto ocorrer, poderá em breve significar perder a liberdade. A segurança e a liberdade são dois valores igualmente preciosos e desejados que podem ser bem ou mal equilibrados, mas nunca inteiramente ajustados e sem atrito. De qualquer modo, nenhuma receita foi inventada até hoje para esse ajuste. O problema é que a receita a partir da qual as 'comunidades realmente existentes' foram feitas torna a contradição entre segurança e liberdade mais visível e mais difícil de consertar.

Deduz-se do acima exposto que viver em comunidade não é estar isento de problemas, mas ter a possibilidade de partilhar dificuldades e encontrar soluções comuns diante dos desafios do cotidiano, a partir do exercício da solidariedade e da alteridade mediante o sentimento de pertença.

No entendimento de Wanderley e Borges (2019, p. 13), o desenvolvimento local deve ser entendido:

[...] como um processo de transformação, no qual o agente protagonista e principal beneficiário é sempre o ser humano. Busca-se, portanto, dentre outros aspectos, a melhoria 
e uma perspectiva de crescimento da qualidade de vida do ser humano como indivíduo, mas também como coletividade, ou de grupo de pessoas que formam uma comunidade.

Entende-se que, quando um sistema cooperativo é implantado em uma localidade, há o desenvolvimento na comunidade, proporcionando ganhos significativos, agregando renda à população e, por consequência, propiciando melhoria na qualidade de vida dos envolvidos. Pode-se até ressaltar que as cooperativas, em sua plena atuação na comunidade, conduzem a uma evolução na vida dos cidadãos envolvidos.

Os princípios do cooperativismo estão em conformidade com aquilo que o desenvolvimento local propugna, notadamente quanto ao envolvimento e à união das pessoas na identificação e resolução dos problemas comuns. No caso específico tratado neste trabalho, a iniciativa das pessoas propiciou a criação da Cooperativa de Crédito Sicredi União MS/TO - Comitê Ação Social, a partir da necessidade de dar resolução a problemas sociais comuns.

Wanderley e Borges (2019, p. 13) afirmam que, a partir da concepção e das consequências de um desenvolvimento que emanam da própria comunidade, e não de forças externas, é possível estabelecer o progresso integral, impulsionando a comunidade local a se desenvolver social e culturalmente na condição de sujeito, e não como mero objeto.

Importante salientar que o desenvolvimento local não se restringe às questões econômicas, mas propugna o desenvolvimento humano com satisfação de suas necessidades básicas.

Em sua teoria, Elizalde (2000) assinala que as necessidades humanas fundamentais não são muitas, são poucas e finitas e, por conseguinte, classificáveis em nove, quais sejam: subsistência, proteção, afeto, entendimento, criação, participação, lazer, identidade e liberdade. Tais necessidades formam um sistema em que uma está inserida na outra, o que poderia ser chamado de natureza humana, não havendo hierarquia entre elas. A visão dominante faz crer que a necessidade fundamental seria a de subsistência, ainda que não se morra apenas de fome, mas também por carência de afeto e de identidade.

Como se pode denotar da assertiva acima, o desenvolvimento local mantém estreita relação com a satisfação das necessidades humanas, o que também está plenamente de acordo com os princípios do cooperativismo.

De outro modo, talvez uma maneira de encontrar um certo equilíbrio entre as necessidades fundamentais do ser humano e o desejo de acumular bens materiais seria desenvolver um raciocínio para demonstrar que nada se leva dos bens materiais ao final da existência, e tais bens fatalmente passarão às mãos de outros e, por último, serão transformados em lixo.

Tal vez una manera de encontrar un cierto equilibrio entre las necesidades fundamentales y el deseo de acumular bienes materiales sería desarrollar un raciocinio para demostrar que nadie se lleva los bienes materiales al final de su existencia y que éstos fatalmente pasarán a las manos de otros y por último serán transformados en chatarra y basura. Además, es bueno recordar que muchos de los bienes se transforman pronto en basura. Es más, hay estudios que miden el grado de desarrollo por la cantidad y tipo de basura, porque "en la medida en que aumenta el ingreso per cápita y por lo tanto el consumo, aumenta la basura. (ELIZALDE, 2000, p. 52).

Frisa-se que as necessidades humanas não dizem respeito unicamente às necessidades de subsistência, de cunho material, mas também às de proteção, de criação e de participação nas atividades da comunidade na qual a pessoa esteja inserida. É claro que, dessas necessidades, há outros fatores que influenciam nas demandas das necessidades humanas, como a construção da 
identidade e o sentimento de pertença em relação a um dado território (WANDERLEY; BORGES, 2019). Ainda em termos semânticos e conceituais, Borges e Hans (2018, p. 27) afirmam que:

O conceito de desenvolvimento local difere de toda e qualquer abordagem genérica e anterior de desenvolvimento. No Brasil, até a década de 1950, quando se implantou de vez a chamada era desenvolvimentista, este era visto como um 'fim buscado' e o fator analisado era principalmente o econômico. [...]. Em se tratando de desenvolvimento local, o desenvolvimento é visto como 'processo', pensando basicamente de forma integrada, sistêmica, agregando-se à sua abordagem múltiplas dimensões, como a econômica, a social, a cultural, a política e a ambiental, entre outras, com características endógenas, pois deve partir de forças locais que se conjugam às demais. Privilegia os aspectos imateriais, como o capital social, o conhecimento, a aprendizagem e a participação dos agentes locais.

Como se pode inferir, o desenvolvimento local implica necessariamente a valorização da cultura local, compreendendo nisso os costumes, as normas legais, a participação das pessoas na resolução dos problemas comunitários, bem como os esforços sinérgicos emanados das potencialidades individuais e coletivas. Para Martins (2002, p. 51),

[...] mais do que um conceito, o desenvolvimento local, é [...] um evento sui generis, resultante do pensamento e da ação à escala humana, que confrontam o desafio de enfrentar problemas básicos e alcançar níveis elementares e auto-referenciados de qualidade de vida na comunidade.

É preciso consubstanciar que o desenvolvimento local subentende o desenvolvimento humano e, para tanto, é preciso que haja formação cultural e educacional voltada para esse fim, sem o que a comunidade ficará sem voz e sem participação.

\section{ESTUDO DE CASO: A COOPERATIVA DE CRÉDITO SICREDI UNIÃO MS/TO}

A Cooperativa de Crédito Sicredi União MS/TO possui o Programa de Inclusão e Estímulo à Participação Social, denominado Sicredi Futuro, que consiste num conjunto de ações e atividades destinadas a públicos específicos, com estrutura, funcionamento e responsabilidades estabelecidos por uma norma.

Na Norma do Programa de Inclusão e Estímulo à Participação Social - Resolução 002/2017, de 19 de maio de 2017 (SICREDI, s.d.), fica explícito o objetivo desse programa:

Este Programa objetiva, desenvolver estimular os associados e as comunidades de atuação da Cooperativa a terem a percepção do voluntariado, da responsabilidade social, contribuição coletiva e participação, além de disseminar o empreendedorismo e o cooperativismo como instrumento de organização e desenvolvimento econômico e social da sociedade.

A cooperativa em apreço conta com três comitês internos nesse programa, o Comitê Ação Social, Comitê Mulher e Comitê Jovem, sendo que somente será estudado o Comitê Ação Social, seu histórico, suas ações e impactos na comunidade local.

No ano de 2010, surgiu o Núcleo dos Aposentados na Cooperativa Sicredi União MS, pela idealização de três servidoras aposentadas da UFMS, sendo elas: Vera Lucia Rodrigues, Aledoina de Arruda Reis e Epomiera Bento. Esse núcleo foi fundado para suprir a necessidade de se obter um centro de convivência para os aposentados da UFMS, pois, na época, havia muitos aposentados que estavam em depressão, desorientados em relação ao que fazer no novo ciclo de suas vidas. No início, o Núcleo dos Aposentados proporcionava cursos profissionalizantes em 
computação, artesanatos e confraternizações no dia do aposentado, sanando, assim, suas horas vagas e atribuindo novas atividades em suas rotinas.

Em 2012, surgiu uma demanda de abertura dessas ações e cursos para atendimento da comunidade, em especial às comunidades carentes da cidade de Campo Grande, MS. Desde então, crianças, jovens, adultos e idosos são beneficiados todos os anos com novas programações desse comitê. Entre os cursos disponibilizados para a comunidade interna e externa, estão os cursos de bordados, pinturas em tecidos, produção de sacolas com garrafas PET, produção de tapetes em teor com restolhos, produção de brinquedos com materiais plásticos descartáveis, confecções de sacolas de banners (ecobags), confecções de mochilas, curso de desossa de frango, confecção de cestas, curso para confeitar bolos, terapia ocupacional e social, curso de informática, confecções de porta-pratos e nécessaires/estojos, sacolas de supermercado e costura.

Logo, em 20 de novembro de 2012, a cooperativa recebeu um certificado de 1 o lugar na etapa estadual da 8a edição do Prêmio Cooperativa do Ano, em Brasília, com o projeto de convivência, certificação esta que alegrou a todos os voluntários desse comitê.

Em 2015, houve uma alteração no nome do Núcleo dos Aposentados, passando a ser Núcleo de Sustentabilidade, porém continuando a exercer as mesmas ações e continuidade na demanda dos cursos disponibilizados, salientando que, no ano de 2017, houve uma formalização por parte da cooperativa, por meio da publicação do documento Norma do Programa de Inclusão e Estímulo à Participação Social (SICREDI,s.d.), Resolução n. 002/2017, de 19/05/2017, denominado Sicredi Futuro.

O Comitê Ação Social, até o final do ano de 2019, já havia atingido mais de 2.000 pessoas, estas alcançadas e beneficiadas com a ajuda de voluntários.

Atualmente, a coordenação geral do programa está sob a direção de Luzia Jorge dos Reis Vergani e a coordenação fica na responsabilidade de Vera Lucia Rodrigues, secretário Alfredo Vicente Pereira e suplente Maura Faustina Borges Santos.

A Norma do Programa de Inclusão e Estímulo à Participação Social - Resolução 002/2017, de 19 de maio de 2017 (SICREDI, s.d.), aborda as competências do Comitê Ação Social destacadas:

a) Estimular a participação dos associados nas ações desenvolvidas;

b) Realizar eventos com atividades profissionais desportiva cultural, artesanal, integrativa e social;

c) Capacitar os associados para atividades manuais e/ou artísticas;

d) Estimular o empreendedorismo e a participação em eventos;

e) Promover ações que vivem saúde, segurança e bem-estar dos associados, segundo a Lei.

f) Planejamento com orçamento até o mês de outubro de cada ano dos eventos/ações do ano seguinte.

Em suma, as competências e o objetivo são totalmente voltados a beneficiar os associados, com extensão à comunidade local. O comitê tem preocupação com a saúde, o bem-estar e a segurança do associado, bem como com a área financeira dele, tendo em vista estimular o empreendedorismo por meio de cursos e palestras realizadas. Além disso, o comitê realiza atividades na comunidade, como entrega de cestas básicas, realização de cursos abertos para a comunidade local e entrega de agasalhos em campanhas, beneficiando-as.

Todos os cursos ministrados atingiram seu objetivo, incentivando o trabalho voluntariado e coletivo, despertando os participantes ao desenvolvimento do empreendedorismo com apelo sustentável, na utilização de materiais, e, por consequência, resultando na geração de renda. 
Correlacionando as ações do Comitê Ação Social com os 7 Princípios do Cooperativismo, obtém-se a percepção do uso contínuo do "7ㅇ. Interesse pela comunidade", utilizando iniciativas autênticas que beneficiam com união, cooperativismo e caráter comunitário a área socioeconômica da população local.

O comitê, ao longo dos anos, tem impactado os associados e a comunidade, mantendo as pessoas em um estado de união e colaboração solidária, unindo-os em ajuda mútua, entre os membros.

O Comitê de Atividades Sociais está sempre envolvido com os cursos oferecidos aos associados e à comunidade e com a confecção de peças artesanais. Alguns quesitos priorizados pelo comitê são a educação, sustentabilidade, agregação de renda, motivação pessoal, espírito de voluntariado e entusiasmo compartilhado, que, de alguma forma, alcançarão os interesses de crianças, jovens, adultos e idosos.

\section{CONSIDERAÇÕES FINAIS}

O objetivo inicial do trabalho evidencia-se pelo estudo do Comitê Ação Social, suas ações e impactos no desenvolvimento local.

Os dados obtidos por esta pesquisa indicam que as cooperativas desempenham um papel de suma importância na comunidade em que estão inseridas, não apenas em documentos publicados e comprometimentos realizados publicamente; revela-se, na prática, que esse interesse pela população reproduz efeitos no desenvolvimento local.

A cooperativa tem cumprido seu objetivo ao alcançar não somente os associados como a comunidade, por meio da aplicação de seus recursos retornados aos associados e enriquecendo as comunidades, proporcionando melhorias nas condições dos indivíduos que ali residem.

Na visão da cooperativa, ela tem um papel importante (por meio do comitê) na contribuição de uma sociedade melhor em que atua o Sicredi. Por se tratar de uma cooperativa, a importância está em buscar uma melhor condição aos associados e à comunidade.

A conclusão do trabalho mostra a importância da atuação do comitê pelas ações e aponta que essas contribuem e agregam valor à sociedade, principalmente para a região onde a cooperativa está inserida.

Dessa forma, fica evidente que a cooperativa como um todo tem desenvolvido suas ações e cumprido com seu papel perante a comunidade, colaborando no desenvolvimento e trazendo ações específicas para melhorar a sociedade.

\section{REFERÊNCIAS}

BARTLE, Phil. O que é comunidade? Uma perspectiva sociológica. 2015. Disponível em: http://cec.vcn. bc.ca/mpfc/whatcomp.htm. Acesso em: 5 mar. 2020.

BAUMAN, Zygmunt. Comunidade: a busca por segurança no mundo atual. Tradução de Plínio Dentzien. Rio de Janeiro: Jorge Zahar Editor, 2012.

BORGES, Pedro Pereira; HANS, Paulo Henrique. A Rádio FM Educativa UCDB 91.5 e o desenvolvimento local: reflexões sobre a responsabilidade social. Campo Grande: Life Editora, 2018.

BRASIL. Lei n. 5764/71, de 16 de dezembro de 1971. Lei geral das cooperativas. Brasília-DF, 1971. Disponível em: https://presrepublica.jusbrasil.com.br/legislacao/109412/lei-5764-71. Acesso em: 3 fev. 2020. 
BUARQUE, Sergio C. Construindo o desenvolvimento local sustentável: metodologia de planejamento. Rio de Janeiro: Garamond, 2002.

ELIZALDE, Antonio. Desarrollo a escala humana: conceptos y experiencia. Interações, Campo Grande, v. 1, n. 1, p. 51-62, 2000.

MARTINS, Sérgio Ricardo Oliveira. Desenvolvimento local: questões conceituais e metodológicas. Interações, Campo Grande, v. 3, n. 5, p. 51-9, 2002.

OLIVEIRA, Sonia. Cooperativismo. Instituto Pólis: 2004. (Boletim Repente, n. 21). Disponível em: http:// www. bibliotecadigital.abong.org.br/bitstream/handle/11465/923/1604. pdf?sequence=1. Acesso em: 27 nov. 2019.

PINHO, Diva B. Lineamento da legislação cooperativa brasileira. São Paulo: CNPq, 1996. (Manual de cooperativismo, v. 3).

RIBEIRO, M. C. Pereira; ALVES, G. R. Rodrigues. Empreendedorismo e inovação: a cooperativa como alternativa empresarial para o desenvolvimento. Londrina v. 14, Scientia luris, v. 14, p. 181-91, nov. 2010. Disponível em: http://www.uel.br/revistas/uel/index.php/iuris/article/view/7656/6750. Acesso em: 27 nov. 2019.

RODRIGUES, Ana Cristina Medeiros; CASTILHO, Maria Augusta. Praça esportiva Belmar Fidalgo: a metamorfose de um estádio de futebol em um espaço sociocultural e esportivo em Campo Grande/MS. Campo Grande: Gráfica Mundial, 2016.

SALES, João Eder. Cooperativismo: origens e evolução. Revista Brasileira de Gestão e Engenharia, São Gotardo, v. 1, p. 23-34, 2010. Disponível em: http://periodicos.cesg.edu.br/index.php/gestaoeengenharia/ article/viewFile/30/23. Acesso em: 27 nov. 2019.

SISTEMA DE CRÉDITO COOPERATIVO [SICREDI]. Histórico. Sicredi, [s.I.], 2020. Disponível em: https://www. sicredi.com.br/html/conheca-o-sicredi/historico/. Acesso em: 29 fev. 2020.

SISTEMA DE CRÉDITO COOPERATIVO [SICREDI]. Estatuto social da cooperativa de crédito, poupança e investimento União dos Estados de Mato Grosso do Sul, Tocantins e Oeste da Bahia. Campo Grande: SICREDI, 2017. Disponível em:

https://www.sicrediuniaomsto.coop.br/estatuto-sicredi-uniao-ms-to. Acesso em: 29 fev. 2020.

SISTEMA DE CRÉDITO COOPERATIVO [SICREDI]. Atividades Sociais. Sicredi, [s.l.], [s.d.]. Disponível em: https://www.sicrediuniaomsto.coop.br/comite-atividades-sociais. Acesso em: 14 fev. 2020.

WANDERLEY, Pedro Paulo Sperb; BORGES, Pedro Pereira. O trabalho do egresso do sistema prisional à luz do desenvolvimento local. Campo Grande: Life Editora, 2019.

\section{Sobre os autores:}

Heitor Romero Marques: Doutorado em Desarrollo Local y Planteamiento Territorial pela Universidad Complutense de Madrid (UCM). Mestre em Educação pela Universidade Católica Dom Bosco (UCDB). Especialista em Filosofia e História da Educação pela Faculdades Unidas Católicas de Mato Grosso (FUCMT). Licenciado em Ciências e Pedagogia pela FUCMT. E-mail: heiroma@ucdb.br, ORCID: http://orcid.org/0000-0003-0093-1617

Jéssica Ojeda da Costa: MBA Executivo em Liderança e Gestão Organizacional pela Universidade Católica Dom Bosco (UCDB). Bacharel em Administração de Empresas pela Universidade 
Federal de Mato Grosso do Sul (UFMS). E-mail: jessicaojeda12@gmail.com, ORCID: http://orcid.org/0000-0002-2602-5391 
